\title{
Kesalahan Penggunaan Tanda Baca dan Kosakata dalam Penulisan Karangan Deskripsi
}

\author{
Desti Alvi Yunita ${ }^{1)}$ \\ Universitas Indraprasta PGRI \\ Jalan Nangka No. 58 C/TB. Simatupang, Tanjung Barat, Jakarta Selatan 12530 \\ Dendy Sugono ${ }^{2)}$ \\ Universitas Indraprasta PGRI \\ Jalan Nangka No. 58 C/TB. Simatupang, Tanjung Barat, Jakarta Selatan 12530 \\ Mamik Suendarti ${ }^{3)}$ \\ Universitas Indraprasta PGRI \\ Jalan Nangka No. 58 C/TB. Simatupang, Tanjung Barat, Jakarta Selatan 12530 \\ yunitadestialvi@gmail.com ${ }^{1)}$
}

\begin{abstract}
The purpose of this study was to determine: 1) Errors in the use of punctuation in the essay description of State Junior High School students in Tangerang Regency. 2) Misuse of vocabulary in the essay description of State Junior High School students in Tangerang Regency. 3) The level of error in the use of punctuation in the essay description of State Junior High School students in Tangerang Regency. 4) The level of error in the use of vocabulary in the essay description of State Junior High School students in Tangerang Regency. The sample used was 60 students with a qualitative descriptive method with non-hypothesis research type. The results showed that: the percentage of errors found in the description essay on the use of dot punctuation (.) $25 \%$, comma (,) $31 \%$, and hyphen punctuation (-) 4\%. Most errors are in the use of comma punctuation marks (,) while the vocabulary errors are $40 \%$. So, the mistakes made by students are less than $55 \%$ so they still need guidance and direction more seriously about the use of spelling and vocabulary in the description essay so that the resulting writing is more appropriate to use ... about the use of punctuation marks (.), Comma punctuation (, ), hyphen (-) and vocabulary.
\end{abstract}

Keywords: Punctuation, Vocabulary, Essay Description

\begin{abstract}
Abstrak
Tujuan penelitian ini adalah untuk mengetahui: 1) Kesalahan penggunaan tanda baca pada karangan deskripsi siswa SMP Negeri di Kabupaten Tangerang. 2) Kesalahan penggunaan kosakata pada karangan deskripsi siswa SMP Negeri di Kabupaten Tangerang. 3) Tingkat kesalahan penggunaan tanda baca pada karangan deskripsi siswa SMP Negeri di Kabupaten Tangerang. 4) Tingkat kesalahan penggunaan kosakata pada karangan deskripsi siswa SMP Negeri di Kabupaten Tangerang. Sampel yang digunakan 60 siswa dengan metode deskriptif kualitatif dengan jenis penelitian non hipotesis. Hasil penelitian menunjukkan bahwa: hasil persentase kesalahan yang ditemukan dalam karangan deskripsi pada penggunaan tanda baca titik (.) $25 \%$, tanda koma (,) $31 \%$, dan tanda baca hubung (-) 4\%. Kesalahan terbanyak terdapat pada penggunaan tanda baca koma (,) sedangkan kesalahan kosakata 40\%. Jadi, kesalahan yang dilakukan siswa kurang dari 55\% sehingga masih perlu bimbingan dan pengarahan lebih serius lagi tentang penggunaan ejaan dan kosakata dalam karangan deskripsi sehingga tulisan yang dihasilkan lebih tepat penggunaanya yaitu tentang penggunaan tanda baca titik (.), tanda baca koma (,), tanda baca hubung (-) dan kosakata.
\end{abstract}

Kata kunci: Tanda Baca, Kosakata, Karangan Deskripsi

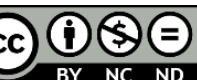

Creative Commons Attribution-NonCommercial-NoDerivatives 4.0 International License 


\section{PENDAHULUAN}

Pendidikan merupakan usaha sadar dan terencana untuk mewujudkan suasana belajar dan proses pembelajaran agar peserta didik secara aktif mengembangkan potensi dirinya untuk memiliki kekuatan spiritual keagamaan, pengendalian diri, kepribadian, kecerdasan, akhlak mulia serta keterampilan yang diperlukan dirinya, masyarakat, bangsa dan negara.

Melalui pendidikan, diri manusia akan tertanam tiga bagian perilaku manusia yaitu, kognitif (ilmu pengetahuan), afektif (sikap), dan psikomotor (keterampilan). Pembelajaran Bahasa Indonesia menekankan pada pemerolehan empat keterampilan berbahasa. Keempat keterampilan tersebut adalah keterampilan menyimak, berbicara, membaca, dan menulis. Keempat keterampilan berbahasa disajikan secara terpadu. Namun dimungkinkan untuk memberikan penekanan pada salah satu keterampilan, misalnya keterampilan menulis.

Keterampilan menulis merupakan urutan yang terakhir dalam proses pembelajaran bahasa setelah keterampilan menyimak, berbicara, daan membaca. Menulis bukan sekedar coretan tinta yang dituangkan dalam buku, namun harus mempunyai makna dan informasi yang akan disampaikan. Pada kenyataannya tidak semua orang mampu menulis karangan dengan baik. Maka keterampilan menulis biasanya dikaitkan dengan pembelajaran mengarang. Melalui kegiatan menulis karangan deskripsi, siswa dapat menceritakan kejadian dengan memberikan gambaran tentang sesuatu berupa benda, tempat, suasana atau keadaan. Kegiatan menulis karangan deskripsi dapat memperluas pengetahuannya melalui tulisantulisannya. Faktor lain yang memengaruhi rendahnya menulis karangan deskripsi pada siswa dikarenakan siswa kurang memahami Ejaan Bahasa Indonesia (EBI).

Rendahnya nilai menulis karangan deskripsi pada siswa merupakan masalah bagi guru. Salah satu upaya pemecahan masalah tersebut adalah dengan menguasai penggunaan tanda baca agar dalam penyusunan karangan deskripsi, tulisan yang disampaikan dapat sesuai peristiwa yang dialami dan sesuai dengan isi karangan yang digambarkan sebuah objek dengan tujuan agar pembaca merasa seolah-olah melihat sendiri objek yang digambarkan itu. Penggunaan tanda baca dalam karangan deskripsi membuat siswa sering mengalami kesalahan terhadap penulisannya. Penulisan tanda baca yang baik dan benar sudah tercantum dalam Permendiknas Nomor 46 tahun 2009. Penggunaan tanda baca dapat membantu siswa untuk meletakan tanda titik (.), tanda koma (,), tanda titik koma (;), tanda titik dua (:), tanda hubung (-), tanda pisah (-), tanda seru (!), tanda kurung $((\ldots))$, tanda kurung siku ([...]), tanda petik ('’...'), tanda petik tunggal(' ..'), tanda garis miring (/), tanda penyingkat atau apostrof (') dalam membentuk penulisan karangan deskripsi yang padu dan sesuai penggunaan tanda baca.

Jenis kesalahan berbahasa yang sering dilakukan siswa berikutnya adalah penggunaan kosakata. Penguasaan kosakata adalah kemampuan atau kemahiran memahami perbendaharaan kata-kata yang dimiliki seseorang baik secara bentuk, isi, serta dalam penggunaannya terhadap bahasa. Melalui kata-kata, kita dapat mengekspresikan pikiran, gagasan, serta perasaan terhadap orang lain. Semakin banyak perbendaharaan kata yang dimiliki, siswa akan dengan mudah untuk menulis. Siswa yang mempunyai kosakata yang banyak akan lebih mudah 
menuangkan idenya dalam bentuk tulisan dibandingkan dengan siswa yang kosakatanya sedikit.

Guru dituntut dapat meningkatkan penguasaan kosakata siswa agar siswa mampu memahami kosakata yang baik. Menulis merupakan salah satu cara untuk meningkatkan penguasaan kosakata. Dengan terbiasa menulis maka siswa terlatih untuk mengembangkan tulisannya dengan memberikan pilihan kata yang relevan dengan topik tulisan. Sebaliknya, keberhasilan penguasaan kosakata yang banyak dapat mengembangkan pola pikir siswa menjadi kritis, kreatif, mampu menuangkan ide, ataupun gagasannya baik secara tertulis maupun secara lisan.

Beberapa kajian mengenai tanda baca dipaparkan sebagai berikut. Chaer (2006:) menyatakan tanda baca adalah tanda-tanda yang digunakan di dalam bahasa tulis agar kalimat-kalimat yang kita tulis dapat dipahami orang persis seperti yang kita maksudkan.

Tanda baca menurut Gani dan Fitriyah (2007:43) menyatakan bahwa tanda baca dapat membantu seseorang dalam memahami isi bacaan. Coba bayangkan jika sebuah teks atau wacana tidak menggunakan tanda baca maka bacaan tersebut tidak dapat dipahami.

Wijayanti (2015: 30) menyatakan tanda baca adalah tanda yang dipakai dalam sistem ejaan (seperti titik, koma, titik dua, dan sebagainya). Tanda baca dapat membantu pembaca untuk memahami makna tulisan dengan tepat. Bayangkan jika tulisan tanpa tanda baca. Pasti tulisan tersebut membingungkan pembaca.Tanda baca tidak dipisahkan dari tulisan. Setiap kali kita menulis pasti menggunakan tanda baca. Tanda baca berfungsi menuntun pembaca untuk memahami bagian-bagian dari kalimat.

Suatu tulisan dengan adanya tanda baca, dapat membantu seseorang memahami kalimat dengan benar. Pemahaman tanda baca harusnya dimiliki oleh setiap orang agar makna yang dihasilkan dari sebuah kalimat akan sampai sesuai dengan yang diinformasikan. Tanda baca selamanya tidak akan pernah berubah atau bertambah karena dalam konsep tanda baca dibagi menjadi 16 tanda baca yang sesuai dengan Ejaan Bahasa Indonesia (EBI).

Tanda baca merupakan bagian dari kaidah ejaan. Fungsi tanda baca dan ejaan sangat menentukan dalam pencapaian tujuan komunikasi. Tanda baca dan ejaan berisikan tentang kaidah-kaidah pemakaian bahasa Indonesia yang baik dan benar, yang sesuai dengan konvensi bahasa yang berlaku. Dalam Ejaan Bahasa Indonesia, semua pemakaian tanda baca sudah diatur. Kaidah pemakaian tanda baca dalam bahasa Indonesia, diantaranya meliputi pemakaian : 1) tanda titik, 2) tanda koma, 3) tanda titik koma, 4) tanda titik dua, 5) tanda hubung, 6) tanda pisah, 7) tanda elipsis, 8)tanda tanya, 9) tanda seru, 10) tanda kurung, 11) tanda kurung siku, 12) tanda petik ganda, 13) tanda petik tunggal, 14) tanda ulang, 15) tanda garis miring, 16) tanda penyingkat(apostrof).

Kosakata merujuk pada kekayaan kata suatu bahasa tertentu. Berdasarkan hal tersebut, terdapat banyak definisi kosakata yang dikemukakan oleh para ahli bahasa. Soedjito dalam Tarigan (2012) menyatakan kosakata dapat diartikan sebagai berikut: (1) semua kata yang terdapat dalam satu bahasa; (2) kekayaan kata yang dimiliki oleh seorang pembicara atau penulis; (3) kata yang dipakai dalam 
suatu bidang ilmu pengetahuan; dan (4) daftar kata yang disusun seperti kamus disertai penjelasan secara singkat dan praktis.

Kosakata yang baik akan menghasilkan perbendaharaan kata yang baik Djiwandono (2011) menyatakan bahwa kosakata adalah perbendaharaan kata-kata dalam berbagai bentuknya yang meliputi: kata-kata lepas dengan atau tanpa imbuhan, dan kata-kata yang merupakan gabungan dari kata-kata yang sama atau berbeda, masing-masing dengan artinya sendiri”.

Chaer (2011) menyatakan bahwa kosakata bahasa Indonesia adalah semua kata yang terdapat dalam bahasa Indonesia. Suatu keterampilan bahasa tidak dapat terlepas dari penguasaan kosakata, sebab inti dari suatu bahasa adalah kata.

Nurgiyantoro (2014) menyatakan bahwa kosakata adalah kekayaan kata yang dimiliki seorang pembicara, penulis, atau suatu bahasa. Kosakata juga merupakan komponen bahasa yang memuat semua informasi tentang makna dan pemakaian kata dalam bahasa.

Kasno (2004) menyatakan bahwa dalam penguasaan kosakata memengaruhi cara berpikir dan kreativitas siswa dalam proses pembelajaran bahasa sehingga penguasaan kosakata dapat menentukan kualitas seorang siswa dalam berbahasa.

Finoza (2004) menyatakan bahwa "karangan merupakan hasil akhir dari pekerjaan merangkai kata, kalimat, dan alinea untuk menjabarkan dan mengulas topik dan tema tertentu". Finoza (2005:192) menyatakan karangan adalah hasil penjabaran suatu gagasan secara resmi dan teratur tentang suatu topik atau pokok bahasan.

Widya dan Sudiati dalam Finoza (2005:192) menyatakan bahwa mengarang adalah keseluruhan rangkaian kegiatan seseorang untuk mengungkapkan gagasan dan menyampaikan melalui bahasa tulis kepada pembaca untuk dipahami.

Menurut Semi dalam Kusumaningsih (2013) menyatakan bahwa deskripsi adalah tulisan yang tujuannya memberikan perincian atau detail tentang objek sehingga dapat memberi pengaruh pada sensivitas dan imajinasi pembaca atau pendengar, bagaikan mereka ikut melihat, mendengar, merasakan atau mengalami langsung objek tersebut.

Resmini (2006) menyatakan bahwa sesuatu yang dideskripsikan tidak hanya terbatas pada apa yang kita lihat dan kita dengar saja, tetapi yang dapat kita rasa dan kita fikir, seperti rasa takut, cemas, tegang, jijik, haru, dan kasih sayang. Begitupula suasana yang timbul dari suatu peristiwa seperti suasana mencekam, putus asa, kemesraan, dan keromantisan panorama pantai.

Finoza (2008) menyatakan bahwa deskripsi adalah bentuk tulisan yang bertujuan memperluas pengetahuan dan pengalaman pembaca dengan jalan melukiskan hakikat objek yang sebenarnya. Dalam bidang karang mengarang, deskripsi dimaksudkan sebagai suatu karangan yang digunakan untuk penulis untuk memindahkan kesan-kesannya, memindahkan hasil pengamatan dan perasaannya, dan disajikan kepada para pembaca.

Tarigan (2005) menyatakan bahwa menulis menurunkan atau melukiskan lambang-lambang grafis yang menghasilkan suatu bahasa yang dipahami oleh seseorang sehingga orang lain dapat membaca lambang-lambang grafis tersebut dan dapat memahami bahasa dan grafis itu. 
Nurgiyantoro (2009) menyatakan bahwa bahasa yang teratur merupakan manifestasi pikiran yang teratur pula. Komunikasi lewat lambang tulis dapat mengungkapkan ide yang diharapkan, penulis hendaklah menuangkan gagasannya ke dalam bahasa yang tepat, teratur, dan lengkap. Karangan Deskripsi banyak dijumpai dalam tulisan-tulisan berbentuk laporan, feature, maupun dalam fiksi. Pembelajaran menulis teks deskripsi dapat membantu siswa dalam melatih kepekaaan karena dengan menulis karangan deskripsi, siswa dapat menjelaskan secara nyata suatu objek ataupun suasana tertentu.

Cara penulisan teks karangan deskripsi dikemukakan oleh Semi (2007) menyatakan bahwa, menggambarkan sesuatu sedemikian rupa sehinggga pembaca dibuat mampu (seolah merasakannya, melihat, mendengar atau mengalami) sebagaimana dipersepsi oleh pancaindra. Pancaindra ikut berperan dalam rincian maka deskripsi sangat mengandalkan pencitraan konkret dan rincian atau spesifikasi".

Dari segi istilah Semi (2007) menyatakan bahwa karangan deskripsi adalah karangan yang tujuannya untuk memberikan rincian atau detail tentang objek sehingga dapat memberi pengaruh pada emosi dan menciptakan imajinasi pembaca bagaikan melihat, mendengar, atau merasakan langsung apa yang disampaikan. Karangan ini bermaksud menyampaikan kesan tentang suatu hal kepada pembaca. Melalui deskripsi, seorang penulis berusaha memindahkan kesan-kesan hasil pengamatan dan perasaannya kepada pembaca dengan membeberkan sifat dan semua perincian yang ada pada sebuah objek.

\section{METODE}

Metode yang digunakan dalam penelitian ini adalah metode deskriptif kualitatif. Djajasudarma (2010: 14) menyatakan bahwa, "Metode kualitatif menjadi titik tolak penelitian kualitatif, yang menekankan kualitas (ciri-ciri data yang alami) sesuai dengan pamahaman deskriptif dan alamiah itu sendiri." Pemilihan metode ini karena sesuai dengan tujuan penelitian secara sistematis, nyata, dan cermat. Metode deskriptif terdiri atas deskriptif kualitatif dan deskriptif kuantitatif. Deskriptif kualitatif yaitu, digambarkan dengan kata-kata atau kalimat yang dipisah-pisah menurut kategori untuk memeroleh simpulan. Sedangkan, deskriptif kuantitatif, yaitu kata yang berwujud angka-angka dan hasil perhitungan atau persentase.

Pendekatan yang digunakan dalam penelitian ini adalah pendekatan kualitatif dengan metode deskriptif analisis. Penelitian ini dilaksanakan di kabupaten Tangerang dengan Ratna (2013: 53) menyatakan, "Pendekatan deskriptif analisis merupakan pendekatan yang dilakukan dengan cara mendeskripsikan faktafakta yang kemudian disusul dengan analisis."

Sugiyono (2011) menyatakan populasi adalah wilayah generalisasi yang terdiri atas beberapa contoh subjek/objek yang mempunyai kuantitas dan karakteristik tertentu yang ditetapkan oleh peneliti untu dipelajari dan kemudian ditarik simpulanya. Subjek dalam penelitian ini adalah siswa Sekolah Menengah Pertama (SMP) di Kabupaten Tangerang. Adapun sampel dari penelitian ini adalah 
siswa kelas VII SMP di Kabupaten Tangerang. Jumlah siswa kelas VII sebanyak 10 kelas, tetapi dalam penelitian ini sampel yang digunakan sebanyak 60 siswa dari dua sekolah yang masing-masing 30 sampel dari setiap sekolah. Uji coba instrumen diambil sebagian siswa kelas VII SMP Negeri 1 Sepatan dan SMP Negeri 2 Sepatan, Kabupaten Tangerang-Banten.

Sehubungan dengan tujuan khusus penelitian, maka peneliti memfokuskan penelitian ini pada: Penggunaan Tanda Baca dan Kosakata dalam Penulisan Karangan Deskripsi Siswa Kelas VII Sekolah Menengah Pertama di Kab.Tangerang, Sedangkan Subfokus terdiri dari kesalahan pengunaan tanda baca dan kosakata yang terdapat dalam karangan deskripsi siswa.

Instrumen yang digunakan untuk pengumpulan data pada penelitian ini, yaitu menggunakan teknik tes, sehingga dari tes mengarang tersebut peneliti mendapatkan data yang responden. Dalam hal ini siswa sebagai responden dijadikan sumber data yang menunjukan kemampuan siswa dalam bidang yang diteliti.

Pelaksanaan penelitian ini disesuaikan dengan jadwal mata pelajaran Bahasa Indonesia kelas VII Sekolah Menengah Pertama di Kab. Tangerang. Dengan tujuan agar tidak mengganggu proses belajar mengajar di kelas yang menjadi tempat penelitian tersebut. Penulis menyiapkan alat penelitian berupa kertas dan pena untuk membuat karangan deskripsi. Karangan deskripsi tersebut terdiri dari paragraf yang telah ditentukan tema dan judulnya oleh penulis. Sebelum tes dilakukan penulis menerangkan karangan deskripsi dan cara mengarang yang baik dan benar.

Setelah tes mengarang, penulis mengumpulkan karangan deskripsi siswa sebagai objek penelitian, membaca karangan siswa dengan teliti, memberi nomor pada setiap karangan, menulis kembali kalimat yang akan diambil ke dalam tabel, menganalisis kalimat berdasarkan kalimat analisis, menghitung dan mempersentasekan stuktur kalimat analisis, interpretasi, dan simpulan.

\section{HASIL DAN PEMBAHASAN}

\section{Hasil}

Berdasarkan penelitian, analisis tanda baca dan kosakata terdapat 56 kesalahan penggunaan tanda baca titik (.), 70 kesalahan penggunaan tanda koma (,), 9 kesalahan pada tanda baca hubung (-) dan terdapat 91 kesalahan penggunaan kosakata, berikut ini uraian analisis. Penafsiran dan uraian penelitian ini dapat dijelaskan berdasarkan analisis dari kesalahan penggunaan tanda baca titik (.), tanda baca koma (,), tanda baca hubung (-) dan penggunaan kosakata yang tidak sesuai dengan kaidahnya. Jadi analisis diperoleh berdasarkan hasil karangan deskripsi kelas VII Sekolah Menengah Pertama di Kabupaten Tangerang dengan memerhatikan penggunaan tanda baca dan penggunaan kosakata.

Penggunaan tanda baca titik (.), tanda baca koma (,) dan tanda baca hubung (-) memiliki fungsi yang berbeda-beda. Siswa terkadang keliru dalam menggunakan tanda baca. Selanjutnya, dalam hal penulisan siswa cenderung keliru dalam menentukan penulisan tanda titik (.) yang seharusnya di akhir kalimat justru 
terbalik dengan fungsi dari tanda koma (,). Tanda koma yang seharusnya ditulis di tengah kalimat ada juga siswa yang menuliskan di akhir kalimat.

Sebaliknya tanda titik yang biasa digunakan di akhir kalimat siswa menuliskan di tengah kalimat yang mengikutinya. Lain halnya dengan tanda hubung dengan kesalahan yang sedikit karena siswa sudah memahami fungsi dari penggunaan tanda hubung pada kalimat yang mereka tulis dalam karangan. Maka penafsiran uraian yang tepat dari hasil analisis data yang ditemukan adalah: Kesalahan penggunaan tanda koma (,) lebih banyak ditemukan hal ini terbukti pada penafsiran dan uraian penelitian ini dapat dijelaskan berdasarkan analisis dari kesalahan penggunaan tanda koma (,) dan penggunaan kosakata yang tidak sesuai dengan kaidahnya.

Berdasarkan data kesalahan pengunaan tanda baca titik (.), tanda baca koma (,), tanda baca hubung (-) yang ditemukan maka persentase yang didapatkan yaitu sebesar:

a. Persentase kesalahan dan ketepatan penggunaan tanda titik (.)
1. Persentase Kesalahan
$=\frac{56}{226} \times 100 \%=25 \%$
2. Persentase Ketepatan
$=100 \%-24,778 \%=75 \%$

b. Persentase kesalahan dan ketepatan penggunaan tanda koma (,)

1. Persentase Kesalahan $\quad=\frac{70}{226} \times 100 \%=31 \%$

2. Persentase Ketepatan= $100 \%-30,973 \%=69 \%$

c. Persentase kesalahan dan ketepatan penggunaan tanda hubung (-)

1. Persentase Kesalahan $\quad=\frac{9}{226} \times 100 \%=4 \%$

2. Persentase Ketepatan $\quad=100 \%-3,98=96 \%$

Berdasarkan tabel di atas menunjukkan tanda koma (,) paling banyak kesalahan penulisannya dalam karangan deskripsi siswa kelas VII Sekolah Menengah Pertama di Kabupaten Tangerang yang berjumlah 70 buah (31\%), tanda titik (.) berjumlah 56 buah (25\%), sedangkan tanda hubung (-) berjumlah 9 buah $(4 \%)$.

Berdasarkan data kesalahan pengunaan kosakata yang ditemukan maka persentase yang didapatkan yaitu sebesar:
1. Persentase Kesalahan$$
=\frac{91}{226} \times 100 \%=40 \%
$$
2. Persentase Ketepatan$$
=100 \%-40,265 \%=58 \%
$$

Berdasarkan tabel diatas menunjukkan tanda koma (,) paling banyak kesalahan penulisannya dalam karangan deskripsi siswa kelas VII Sekolah Menengah Pertama di Kabupaten Tangerang yang berjumlah 70 buah (31\%)

\section{PENUTUP}

Berdasarkan hasil pembahasan analisis pada Bab IV data terhadap 60 karangan siswa yang dijadikan sampel dalam penelitian ini, maka dapat disimpulkan bahwa hasil analisis dari kesalahan penggunaan tanda baca menunjukkan penulisan 
tanda koma (,) banyak kesalahan dalam penulisan dalam karangan deskripsi. Salah satunya disebabkan dalam penggunaan tanda koma (,), siswa masih kurang memahami pemakaian tanda baca. Penggunaan tanda titik (.) dan tanda hubung (-) terjadi kesalahan namun tidak terlihat banyak kesalahan, ini berarti siswa-siswi mudah memahami penggunaan tanda baca titik (.) dan tanda hubung (-), hasil analisis dari kesalahan yang sering muncul dalam penggunaan kosakata dalam menulis karangan deskripsi adalah ketidakbakuan dan ketidakefektifan kata yaitu kata shalat dan mushola seharusnya menjadi salat dan musala, tingkat kesalahan penggunaan tanda baca meliputi tanda titik (.) $25 \%$, tanda koma (,) $31 \%$, tanda hubung (-) 4\%, dan tingkat kesalahan penggunaan kosakata pada penulisan teks karangan deskripsi sebesar $40 \%$.

Berdasarkan simpulan di atas, penelitian ini menggambarkan bentuk kesalahan dalam penggunaan tanda baca titik (.), tanda baca koma (,), tanda baca hubung (-) dalam karangan deskripsi siswa, dapat diungkapkan beberapa saran, yaitu guru sebaiknya mengoreksi hasil karangan siswa secara terperinci terutama dalam penggunaan tanda baca dan kosakata, hasil karangan yang telah dikoreksi dikembalikan kepada siswa agar mereka mengetahui kesalahannya, dan guru harus berusaha keras dalam membina, membimbing dan mempersiapkan bahan mengajar sebelum melaksanakan pembelajaran agar siswa memiliki pengetahuan dan keterampilan berbahasa tulis dengan lebih bagus lagi.

\section{DAFTAR PUSTAKA}

Chaer, A. (2006). Tata bahasa praktis bahasa Indonesia. Jakarta: PT Rineka Cipta. Chaer, A. (2011). Tata bahasa praktis bahasa Indonesia. Jakarta: Rineka Karya.

Departemen Pendidikan Nasional. (2008). Kamus Besar Bahasa Indonesia. Jakarta: PT Gramedia Pustaka Utama.

Djajasudarma. (2010). Metode lingustik: Ancangan metode penelitian dan kajian. Bandung: Reflika Aditama.

Djiwandono, S. (2011). Tes bahasa pegangan bagi pengajar bahasa. Jakarta: Indeks. Finoza, L. (2004). Komposisi bahasa Indonesia. Jakarta: Insan Mulia.

Finoza, L. (2005). Komposisi bahasa Indonesia. Jakarta: Diksi dan Insan Mulia.

Finoza, L. (2008). Komposisi bahasa Indonesia untuk mahasiswa nonjurusan bahasa. Jakarta: Rineka Cipta.

Gani, A. R. \& A. Mahmudah F. Z. (2007). Pembinaan bahasa Indonesia. Jakarta: UIN Jakarta Press.

Kasno. (2004). Kamus sebagai sumber rujukan dan pengajaran kosakata. Jakarta: Pusat Bahasa.

Kusumaningsih, D., Sudiatmi, T., \& Mulyati, S. (2013). Terampil berbahasa Indonesia. Yogyakarta: CV. Andi Offset.

Nurgiantoro, B. (2009). Penelitian pembelajaran berbasis kompetensi. Yogyakarta: BPFE.

Nurgiantoro, B. (2014). Penilaian dalam pengajaran bahasa dan sastra. Yogyakarta: BPFE. 
Ratna, N. K. (2013). Teori, metode dan teknik penelitian sastra. Yogyakarta: Pustaka Pelajar.

Resmini, N., Churiyah, Y., \& Sundori, N. (2006). Membaca dan menulis di SD: Teori dan pengajarannya. Reading and writing in elementary school: theory and teaching]. Bandung, Indonesia: UPI Press.

Semi, M. A. (2007). Dasar-dasar keterampilan menulis. Bandung: Angkasa

Sugiyono. (2011). Metode penelitian kuantitatif kualitatif dan R\&D. Bandung: Alfabeta.

Tarigan, H. G. (2005). Keterampilan menulis. Bandung: Angkasa.

Tarigan, H. G. (2012). Penguasaan kosakata dalam kinerja bahasa. Bandung: Rosdakarya.

Wijayanti, S. H., Candrayani, A., Hendarwati, I. E. S., \& Agustinus, J. W. (2013). Bahasa Indonesia: Penulisan dan penyajian karya ilmiah. Raja Grafindo Persada. 